\title{
Association of chemotactic factor receptor 5 gene with breast cancer
}

\author{
Y. Zhang ${ }^{1}$, F.Y. Meng ${ }^{2}$, W.L. Li ${ }^{1}$, C.X. Zhou ${ }^{1}$, Z. Guan ${ }^{1}$ and H.Y. Fan ${ }^{2}$ \\ ${ }^{1}$ Department of Breast and Thyroid Surgery, People's Hospital of Liaocheng, \\ Liaocheng, Shandong, China \\ ${ }^{2}$ Medical College of Liaocheng Vocational and Technical School, \\ Shandong, China \\ Corresponding author: Y. Zhang \\ E-mail: zhangyang5366@yeah.net
}

Genet. Mol. Res. 12 (4): 5289-5300 (2013)

Received January 14, 2013

Accepted August 26, 2013

Published November 7, 2013

DOI http://dx.doi.org/10.4238/2013.November.7.4

\begin{abstract}
We designed a 2-stage study to investigate chemotactic factor receptor 5 (CCR5) gene expression in breast cancer tissues and axillary lymph nodes and analyze the association between the CCR5- $\triangle 32$ gene polymorphism and the clinical features and prognosis of breast cancer patients. The first stage examined 72 cases of invasive ductal carcinoma and axillary lymph node tissue, 50 cases of breast fibroadenoma tissue, and 40 cases of normal breast tissue. The tissues specimens were embedded in paraffin, and CCR5 expression was detected using immunohistochemical methods. C-erbB-2, p53, Ki67, estrogen receptor, and progesterone receptor expression were also detected in the breast cancer tissues. The second stage examined 35 cases of surgically removed tissue. Relative expression levels of CCR5 messenger RNA (mRNA) in primary foci, axillary lymph node, and cancer-adjacent tissues of the breast cancer and breast fibroadenoma samples were detected using real-time quantitative reverse transcriptionpolymerase chain reaction assay. We found that 1) CCR5 mRNA relative expression levels in breast cancer tissue were significantly higher than those in adjacent normal tissue $(\mathrm{P}<0.01)$ and benign
\end{abstract}


tumors $(\mathrm{P}<0.05)$. The relative CCR5 mRNA relative expression level between phase II and phase III breast cancer tissues was statistically significant $(\mathrm{P}<0.05)$. The CCR5 mRNA relative expression level between adjacent normal tissues and fibroadenoma tissues was not significantly different $(\mathrm{P}>0.05)$. 2) Relative CCR5 mRNA expression level was significantly higher in metastatic lymph node tissues than that in non-metastatic lymph nodes $(\mathrm{P}<0.05)$, and 3$)$ CCR5 expression in breast cancer tissue was positively correlated with axillary lymph node metastasis (chi-square $=4.982, \mathrm{P}=0.026, \mathrm{r}=0.305$ ). $\mathrm{CCR} 5$ expression was mildly and positively correlated with the oncogene C-erbB-2 (P $<0.05, \mathrm{r}=0.291)$. 4) CCR5 expression in breast cancer tissue was not correlated with age, menopause, maximum tumor size, tumor phase, p53, Ki-67, estrogen receptor, progesterone receptor, or other clinical features $(\mathrm{P}>0.05)$. We concluded that CCR5 expression significantly increases in breast cancer tissues and metastatic lymph nodes. CCR5 plays a role in breast cancer development and axillary lymph node metastasis. It can be used indirectly as an indicator of axillary lymph node metastasis and prognosis.

Key words: Breast cancer; CCR5; C-erbB-2; Ki-67; Prognostic indicator; Immunohistochemistry

\section{INTRODUCTION}

Metastasis is a main cause of death in breast cancer patients. In recent years, the association between chemokines and their receptors and breast cancer has become a hot topic, particularly the interactions between $\mathrm{CXC}$ chemokine receptor 4 and chemotactic factor receptor (CCR) 7 receptors and their ligands. Studies of their effects on other biological protein factors to regulate the occurrence, progression, and metastasis of breast cancer have provided rich data and a basis for the targeted treatment of breast cancer (Loetseher et al., 1998). However, reports of the association between CCR5 and breast cancer are limited. CCR5 is a specific receptor for chemokines macrophage inflammatory proteins $1 \alpha$ and $1 \beta$ and RANTES (regulated on activation, normal $\mathrm{T}$ cell expressed and secreted). CCR5 binds with its specific ligands to activate $\mathrm{G}$ protein and ultimately increase intracellular $\mathrm{Ca}^{2+}$ concentration and activate protein kinase $\mathrm{C}$, which is expressed as leukocyte chemotaxis and inflammatory response and has other physiological functions (Loetseher et al., 1998). CCR5 and its ligands are reportedly associated with mammary tumor growth, metastasis, and infiltration of mononuclear cells (Azenshtein et al., 2002). CCR5- 332 is a 32-bp deletion in the 185-amino acid codon of the CCR5 allele-coding region. Its relationship with breast cancer remains unclear. A study by Azenshtein et al. (2002) has shown that the concentration of RANTES in the serum of breast cancer patients is usually elevated. CCR5 ligands may cause chemotaxis of CCR5-expressing tumor cells into blood circulation, which contributes to the transfer of cancer cells to target organs. Owing to the complexity of the chemotactic factor receptor network and tumor growth and metastasis, the role that CCR5 plays in the development of breast cancer must be further explored. 
In the present study, we used real-time quantitative reverse transcription-polymerase chain reaction (RT-PCR) to detect the relative expression levels of CCR5 mRNA in breast cancer tissues, axillary lymph nodes, adjacent normal tissues, and fibroadenoma tissues. We then detected the allele frequency of CCR 5- $\triangle 32$ and further explored the expression of CCR5 in the metastasis and axillary lymph nodes of breast cancer. Herein, we also discuss its association with clinicopathological parameters and other commonly used prognostic indicators.

\section{MATERIAL AND METHODS}

\section{General information}

This study was divided into 2 stages. The 1st stage examined 72 cases of archive wax block specimens from patients who had modified radical mastectomy at Liaocheng People's Hospital (Shandong, China) between October 1, 2006, and July 31, 2007. The specimens were confirmed with conventional pathological tests as breast invasive ductal carcinoma. Fifty cases had axillary lymph node metastasis. All 72 cases were from women aged 27 to 78 years (average, $50.33 \pm 10.69$ years) who received no chemotherapy, radiotherapy, or other treatment before surgery. The tumor-node-metastasis stages of these patients established by the American Joint Committee on Cancer (6th edition, 2002) were as follows: 23 cases of stage I, 30 cases of stage II, and 19 cases of stage III. We selected 50 cases of breast fibroadenoma from patients who received surgery at the same time and 40 cases of normal breast tissue ( 5 $\mathrm{cm}$ away from the edge of the breast cancer tissue) as the controls.

The 2nd stage of the study involved the analysis of 35 cases of surgically removed and pathologically confirmed invasive ductal carcinoma from patients at Liaocheng People's Hospital between August 2008 and June 2009. All of the patients were females aged 30 to 70 years. Axillary lymph node metastasis was found in 28 cases, and metastasis was absent in 7 cases. The specimens were rapid sampled in vitro and kept at $-80^{\circ} \mathrm{C}$. We then obtained cancer-adjacent normal tissue (confirmed through pathology) with edges of $>5 \mathrm{~cm}$ from cancer tissue and 21 cases of fibroadenoma tissue as the controls. We also obtained 20 cases of pathologically confirmed cancer metastasis axillary lymph node tissue and selected 13 cases of non-metastatic lymph node tissues as the control. The patients had received no preoperative radiotherapy, chemotherapy, or other treatments. The tumor-node-metastasis stages of these patients established by Union for International Cancer Control were as follows: 12 cases of stage II, 21 cases of stage III, and 2 cases of stage IV.

\section{Experimental methods}

\section{Immunohistochemical staining}

We followed the methods of Li et al. (2009). CCR5 immune staining was performed on the breast lesions, axillary lymph node metastatic lesions, breast fibroadenoma tissue, and normal breast tissue. The same method was used to detect the expression of estrogen receptors (ERs), progesterone receptor (PRs), C-erbB-2, p53, and Ki-67 in breast cancer tissues. CCR5 mouse anti-human monoclonal antibodies were purchased from R\&D Company (GENTEC N.V. Oeverstraat 21B- 9160 Lokeren. Lot AJB12). The rabbit anti- 
mouse secondary antibody and the 3,3'-diaminobenzidine staining kit were purchased from Fujian Maixin Biotechnology Development Co., Ltd. (Fujian, China.). The paraffin blocks were sliced into 6- $\mu \mathrm{m}$ serial sections, and the Streptavidin-perosidase (SP) method was used to detect CCR5 expression. CCR5 is located in the membrane or cytoplasm of breast cancer cells. The appearance of light yellow to brownish-yellow granules in the membrane or the cytoplasm of the cancer cells is considered positive staining. The cellular localization varies with different immunohistochemical indicators. At low magnification, we selected the intensive areas of the cancer cells with positive protein staining. Cell counting was then performed in 5 randomly selected horizons with a 200X light microscope. The percentage of protein-positive cells in the tumor samples was used as the indicator of staining degree. The obviously stained, and positive rate of cell staining in $>20 \%$ of the tissues were regarded as positive expression. No staining or a positively stained rate of $<20 \%$ of the tissues was defined as negative expression.

C-erbB-2 is located in the membrane of breast cancer cells. We used "“-" to denote no membrane staining of the tumor tissues or membrane staining of $\leq 10 \%$. We used "+" to define partial membrane staining of $>10 \%$ of the tumor cells, "++" for weak to moderate staining of $>10 \%$ of the tumor cells, and "+++" for full staining of $>10 \%$ of the tumor cells. The "+" and "+++" stood for overexpression, the "-" and "+" stood for negative expression. The test results of p53, Ki-67, ERs, PRs were interpreted according to kit instructions (Fujian Maixin Biotechnology Development Co., Ltd).

\section{Real-time quantitative RT-PCR analysis}

\section{Primers}

The RT-PCR amplification primer sequences were synthesized by Shanghai Sangon Technology Company. The sequence of the upstream primer P1 was 5'-CAGATCTCAAAAA GAAGGTCT-3'. The sequence of the downstream primer P2 was 5'-GATGTGTAAGATAAG CCTCAC-3'.

\section{Total RNA extraction and first-strand complementary DNA synthesis}

Total cellular RNA was extracted using the Trizol method. The RNA was dissolved in $30 \mu \mathrm{L}$ diethylpyrocarbonate double-distilled water and stored at $-80^{\circ} \mathrm{C}$. The RT system was as follows: $15 \mu \mathrm{L}$ total cellular RNA, $7 \mu \mathrm{L}$ RT $5 \mathrm{X}$ buffer, $5 \mu \mathrm{L} 40 \mathrm{U} / \mu \mathrm{L}$ RNAsin (Sangon Biotech Co., Ltd., Shanghai, China), $1 \mu \mathrm{L} 10 \mathrm{mM}$ deoxyribonucleotide triphosphate, $1 \mu \mathrm{L} 100 \mu \mathrm{M}$ Oligo (dT18) primer, and $1 \mu \mathrm{L} 200 \mathrm{U} / \mu \mathrm{L}$ Moloney murine leukemia virus reverse transcriptase. The mixed system was kept at $42^{\circ} \mathrm{C}$ in a water bath for $45 \mathrm{~min}$ and then in a $95^{\circ} \mathrm{C}$ water bath for 5 min to inactivate the reverse transcriptase. After the reaction, the RT products were stored at $-20^{\circ} \mathrm{C}$.

\section{Fluorescence quantitative real-time RT-PCRs and data analysis}

During target gene amplification, the housekeeping gene $\beta$-actin was used as the internal reference. SYBR GreenI (Sangon Biotech Co., Ltd., Shanghai, China) was se- 
lected as the fluorescent dye. The total reaction system was $50 \mu \mathrm{L}: 25 \mu \mathrm{L} 2 \mathrm{X}$ PCR master mix, $21 \mu \mathrm{L}$ double-distilled water, $1 \mu \mathrm{L}$ template complementary DNA, $1 \mu \mathrm{L}$ primer on each stream $(1 \mu \mathrm{M})$, and $1 \mu \mathrm{L}$ SYBR GreenI. The reaction conditions were as follows: pre-denaturation at $94^{\circ} \mathrm{C}$ for $30 \mathrm{~s}$; denaturation at $94^{\circ} \mathrm{C}$ for $30 \mathrm{~s}$, annealing at $60^{\circ} \mathrm{C}$ for 30 $\mathrm{s}, 72^{\circ} \mathrm{C}$ extension for $30 \mathrm{~s} ; 40$ cycles were included. An ABI7300 quantitative PCR instrument was used for the detection. Threshold $(\mathrm{Ct})$ value was analyzed with Eppendorf Realplex 4 software. The $F=2^{-\Delta \Delta t}$ method was used to calculate the relative expression level.

\section{Specific detection of amplified DNA}

Melting curve analysis was used to test the amplified DNA. Specificity was detected using $1.5 \%$ agarose gel electrophoresis.

\section{CCR5-432 allele detection}

The amplified DNA was analyzed using 1.5\% agarose gel electrophoresis and an AlphaImager 2200 gel imaging system.

\section{Statistical analysis}

Statistical analysis was performed using SPSS 13.0 software. Data are reported as means $\pm \mathrm{SE}$. The $\mathrm{Ct}$ method was used for the relative quantitative comparisons. The $\Delta \mathrm{ct}$ values represented the $\mathrm{Ct}$ value difference between the target gene and the housekeeping gene in the same sample. The $\Delta \Delta \mathrm{ct}$ values represented the difference between the 2 groups of $\Delta \mathrm{ct}$. The calculation $\mathrm{F}=2^{-\Delta \Delta \mathrm{ct}}$ represented the ratio of the gene copy number between the 2 groups. The $2^{-\Delta c t}$ value was analyzed with 1-way analysis of variance and independent-sample $t$-test. A P value of $<0.05$ was considered to be statistically significant.

\section{RESULTS}

\section{CCR5 expression in normal breast and tumor tissues}

CCR5 expression was absent in normal breast tissues as well as in the majority of breast fibroadenoma tissues, in which only a small portion displayed low expression. The positive rate was $14 \%(7 / 50)$. The positive rate of CCR 5 protein expression in breast cancer tissues was $84.72 \%(61 / 72$; Table 1, Figure 1).

\begin{tabular}{|c|c|c|c|c|}
\hline \multirow[t]{2}{*}{ Groups } & \multicolumn{3}{|c|}{ CCR5 } & \multirow{2}{*}{$P$ value } \\
\hline & $\mathrm{N}$ & Positive cases (\%) & Negative cases (\%) & \\
\hline Breast fibroadenoma & 50 & $7(14.00)$ & 43 & \multirow[t]{3}{*}{$\begin{array}{c}\mathrm{P}<0.001 \\
\left(\chi^{2}=59.82\right)\end{array}$} \\
\hline Breast Cancer & 72 & $61(84.72)$ & 11 & \\
\hline Total & 122 & 68 & 54 & \\
\hline
\end{tabular}


A

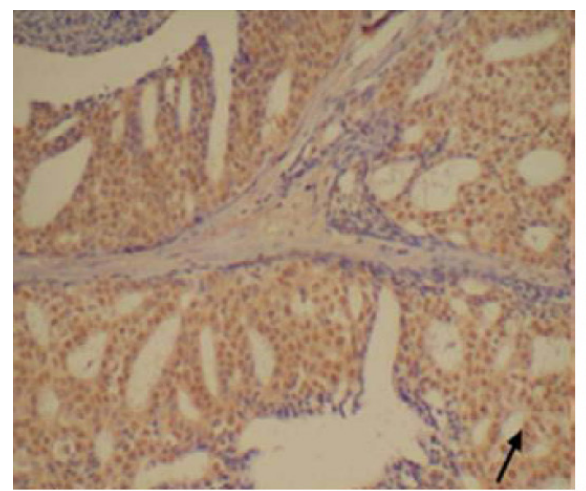

C

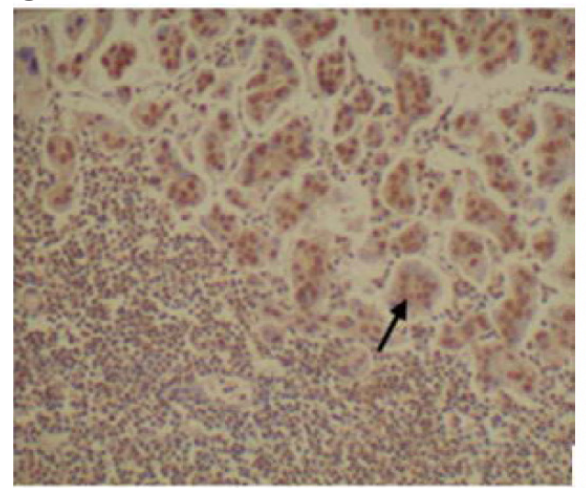

B

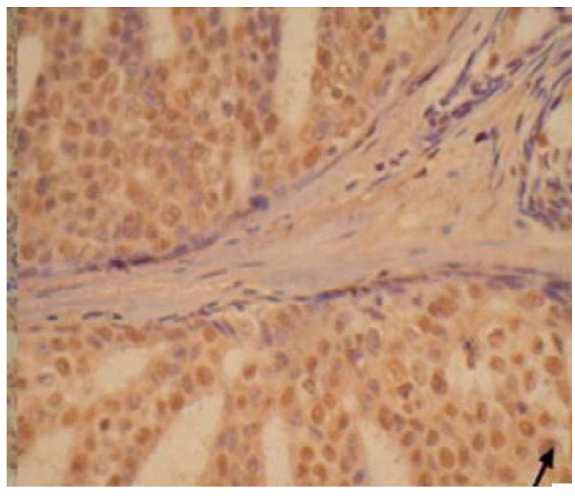

D

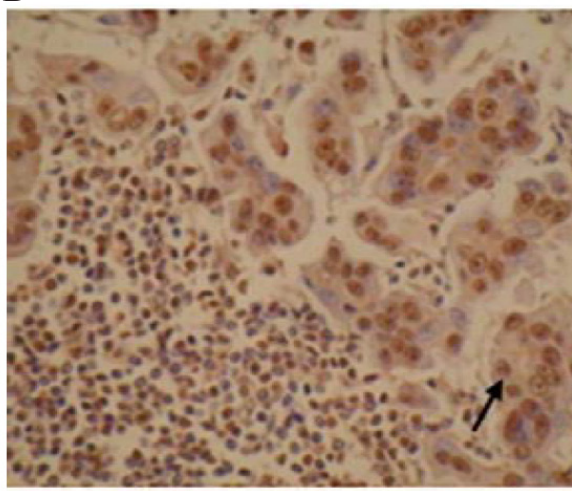

Figure 1. CCR5-positive expression is in the cell membrane or cytoplasm. A. CCR5-positive expression of the breast primary tumor (SP staining 100X). B. CCR5-positive expression of the breast primary tumor (SP staining 200X). C. CCR5-positive expression of the metastatic axillary lymph nodes of the breast cancer (SP staining 100X). D. CCR5-positive expression of the metastatic axillary lymph nodes of the breast cancer (SP staining 200X).

\section{CCR5 mRNA expression among various tissues}

\section{RT-PCR-specific test of amplified DNA}

The quantitative PCR melting curve showed that the products of CCR5 and $\beta$-actin had a single sharp peak. The melting temperatures of the CCR5 and $\beta$-actin genes were 77.3 and $81.2^{\circ} \mathrm{C}$, respectively. No amplification product was found in the negative control (Figure 2A). Agarose gel electrophoresis showed a single band of the CCR5 and $\beta$-action amplification products, which verified the specificity of the reaction (Figure 2B).

\section{CCR5 mRNA expression}

The CCR5 mRNA expression in breast cancer was significantly higher than that in the tumor-adjacent normal tissue, and the difference was statistically significant $(0.0836 \pm$ 
0.03 vs $0.0647 \pm 0.03, \mathrm{P}<0.01, \mathrm{t}=2.6355)$. Significant difference was found in CCR5 mRNA expression in the breast cancer tissues and that in the fibroadenoma tissues $(0.0836 \pm 0.03 v s$ $0.0648 \pm 0.03, \mathrm{P}<0.05, \mathrm{t}=2.2703)$. No significant difference in CCR5 mRNA expression was observed in the tumor-adjacent tissues and the fibroadenoma tissues $(0.0648 \pm 0.03$ vs 0.0647 $\pm 0.03, \mathrm{P}=0.986, \mathrm{t}=0.0121$; Figure $3 \mathrm{~A}$ ).
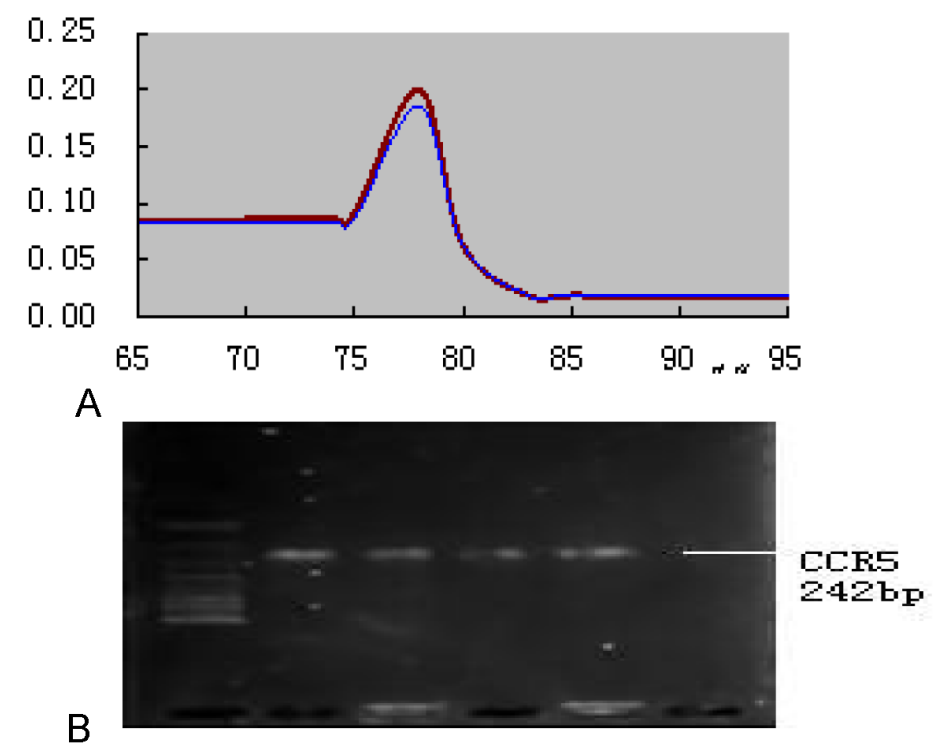

Figure 2. A. Specific detected melting curve of the RT-PCR amplified DNA (CCR5). B. Specific detected electrophoresis of the RT-PCR amplified DNA.

\section{CCR5 mRNA expression in metastatic and non-metastatic lymph nodes}

CCR5 mRNA expression showed significant difference between metastatic and nonmetastatic lymph nodes $(0.1520 \pm 0.06 v s 0.1130 \pm 0.03, \mathrm{P}<0.05, \mathrm{t}=2.1658$; Figure $3 \mathrm{~B})$.

\section{CCR5 mRNA expression in breast cancer tissues at various stages}

CCR5 mRNA expression was significantly higher in stage III breast cancer patients than that in stage II patients, and the difference was statistically significant $(0.0885 \pm 0.02$ vs $0.0667 \pm$ $0.03, \mathrm{P}<0.05, \mathrm{t}=2.507$; Figure $3 \mathrm{C}$ ). The CCR5- $\Delta 32$ allele was not found in any of the samples.

\section{Relationship between CCR5 expression and clinicopathological parameters in breast cancer}

CCR5 expression was unassociated with age, menopause, maximum tumor size, tumor stage, or any other clinical features, and differences between these indicators were not statistically significant among the groups $(\mathrm{P}>0.05)$. However, CCR5 expression was positively correlated with axillary lymph node metastasis, and significant differences were found among the groups with the metastasis status (chi-square $=4.982, \mathrm{P}=0.026, \mathrm{r}=0.305$; Table 2). 


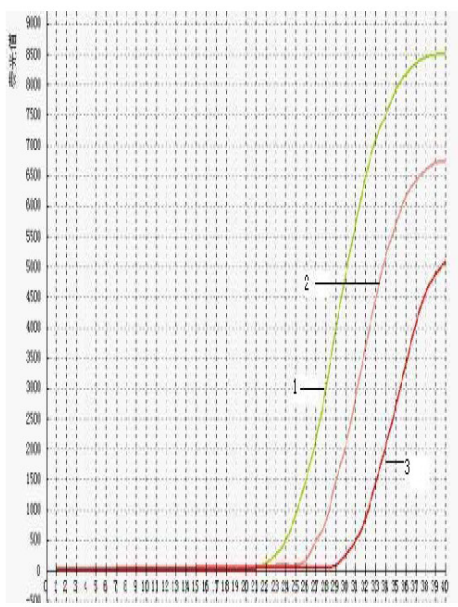

A

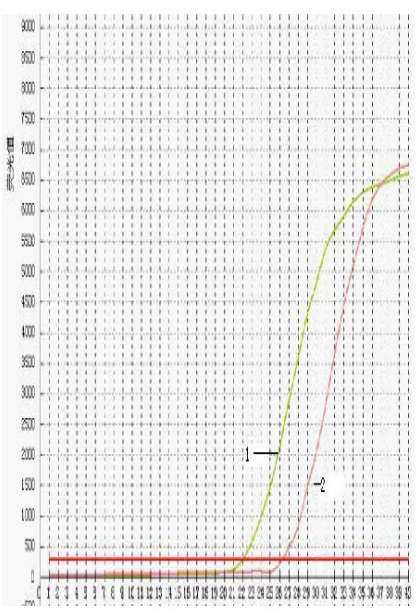

B

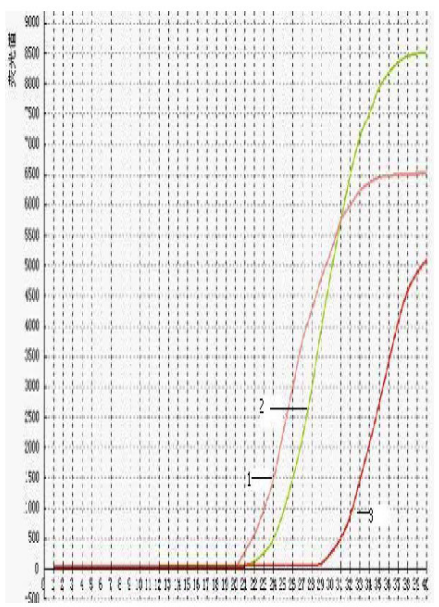

C

Figure 3. A. RT-PCR amplification curves - breast cancer and fibroadenoma tissues, paraneoplastic tissues $(1=\beta$-actin; 2 = breast cancer tissues; 3 = fibroadenoma/paraneoplastic tissues). B. RT-PCR amplification curve - metastatic and non-metastatic lymph nodes ( $1=$ metastatic lymph nodes; $2=$ non-metastatic lymph nodes $)$. C. RT-PCR amplification curve - phase II, of the breast cancer tissues $(1=\beta$-actin; $2=$ phase III of the breast cancer tissues; 3 = phase II of the breast cancer tissues).

Table 2. The relationship between the CCR5 expression and the clinicopathological parameters.

\begin{tabular}{|c|c|c|c|c|c|c|c|}
\hline \multirow[t]{2}{*}{ Clinicopathological parameters } & \multicolumn{2}{|c|}{ CCR5 } & \multirow[t]{2}{*}{ Total } & \multirow[t]{2}{*}{ Positive rate (\%) } & \multirow[t]{2}{*}{$\chi^{2}$} & \multirow[t]{2}{*}{ P value } & \multirow[t]{2}{*}{$\mathrm{r}$} \\
\hline & + & - & & & & & \\
\hline \multicolumn{8}{|l|}{ Age (years) } \\
\hline$\geq 45$ & 41 & 7 & 48 & 85.4 & $<0.001$ & $\mathrm{P}=1.000$ & 0.027 \\
\hline$<45$ & 20 & 4 & 24 & 83.3 & & & \\
\hline \multicolumn{8}{|l|}{ Diameter $(\mathrm{cm})$} \\
\hline$\leq 2$ & 33 & 8 & 41 & 80.5 & 0.669 & $P=0.413$ & 0.135 \\
\hline$>2$ & 28 & 3 & 31 & 90.3 & & & \\
\hline \multicolumn{8}{|l|}{ Menopause } \\
\hline No & 33 & 6 & 39 & 84.6 & 0.001 & $\mathrm{P}=0.978$ & 0.003 \\
\hline Yes & 28 & 5 & 33 & 84.8 & & & \\
\hline \multicolumn{8}{|l|}{ Phases } \\
\hline I-II & 44 & 9 & 53 & 83.0 & 0.090 & $P=0.765$ & 0.079 \\
\hline III & 17 & 2 & 19 & 89.5 & & & \\
\hline \multicolumn{8}{|l|}{ Axillary lymph node metastasis } \\
\hline+ & 46 & 4 & 50 & 92.0 & 4.982 & $\mathrm{P}=0.026$ & 0.305 \\
\hline - & 15 & 7 & 22 & 68.2 & & & \\
\hline
\end{tabular}

\section{Relationship between CCR5 expression and commonly used oncogene prognostic indicators}

CCR5 expression was positively correlated with the oncogene C-erbB-2 $(r=0.291$, $\mathrm{P}<0.05$ ) but was not correlated with the expression of the tumor suppressor gene $\mathrm{p} 53$. It was also not correlated with the tumor proliferation fraction Ki-67, ER, or PR (Tables 3 and 4). 


\begin{tabular}{|c|c|c|c|c|c|c|}
\hline \multirow[t]{2}{*}{ Gene } & \multicolumn{2}{|c|}{ CCR5 } & \multirow[t]{2}{*}{ Total } & \multirow[t]{2}{*}{ Positive rate (\%) } & \multirow[t]{2}{*}{$P$ value } & \multirow[t]{2}{*}{$\mathrm{r}$} \\
\hline & + & - & & & & \\
\hline \multicolumn{7}{|l|}{ C-erbB-2 } \\
\hline Overexpressed & 30 & 1 & 31 & 96.8 & $\mathrm{P}=0.032$ & 0.291 \\
\hline Negatively expressed & 31 & 10 & 41 & 75.6 & $\left(\chi^{2}=4.583, P=0.032\right)$ & \\
\hline
\end{tabular}

\begin{tabular}{|c|c|c|c|c|}
\hline \multirow[t]{2}{*}{ Immunohistochemical indicators } & \multicolumn{2}{|c|}{ CCR5 } & \multirow[t]{2}{*}{$P$ value } & \multirow[t]{2}{*}{$\mathrm{r}$} \\
\hline & + & - & & \\
\hline \multicolumn{5}{|l|}{ C-erbB-2 } \\
\hline+ & 30 & 1 & $\left(\chi^{2}=4.583, P=0.032\right)$ & 0.291 \\
\hline - & 31 & 10 & & \\
\hline \multicolumn{5}{|l|}{$\mathrm{p} 53$} \\
\hline+ & 23 & 6 & $\left(\chi^{2}=0.510, P=0.475\right)$ & -0.124 \\
\hline- & 38 & 5 & & \\
\hline \multicolumn{5}{|l|}{ Ki-67 } \\
\hline+ & 36 & 10 & $\left(\chi^{2}=2.843, P=0.092\right)$ & -0.239 \\
\hline- & 25 & 1 & & \\
\hline \multicolumn{5}{|l|}{ ER } \\
\hline+ & 36 & 7 & $\left(\chi^{2}<0.001, P=1.000\right)$ & -0.034 \\
\hline - & 25 & 4 & & \\
\hline \multicolumn{5}{|l|}{ PR } \\
\hline+ & 32 & 7 & $\left(\chi^{2}=0.469, P=0.493\right)$ & -0.081 \\
\hline- & 29 & 4 & & \\
\hline
\end{tabular}

\section{CCR5 expression in primary breast tumor and metastatic lymph nodes}

Among the 72 cases of breast cancer and axillary lymph node tissues examined, 61 cases displayed positive primary foci staining ( $84.72 \%$ ). Among these positives, 46 cases displayed lymph node metastasis and 15 cases lacked lymph node metastasis. The metastasis rate was $75.41 \%$. Among the 11 cases of negative staining, 4 cases had lymph node metastasis. The metastasis rate was $36.36 \%(\mathrm{P}<0.05)$. Among the 50 patients with axillary lymph node metastasis, the CCR5-positive expression rate of the primary and metastatic foci was $92 \%$ $(46 / 50)$ and $80 \%(40 / 50)$ respectively (Table 5$)$.

Table 5. CCR5 expression in the primary foci and metastatic lymph nodes of the breast cancer (cases).
\begin{tabular}{lccc}
\hline CCR5 expression in metastatic lymph nodes & CCR5 expression in the primary foci & P value \\
\cline { 2 - 4 } & + & 1 & - \\
\hline$+(\mathrm{N}=40)$ & 39 & 3 & $0.022^{*}$ \\
$-(\mathrm{N}=10)$ & 7 & 3 \\
\hline
\end{tabular}

*Fisher's exact test, $\mathrm{P}=0.02, \mathrm{C}=0.38$.

\section{CCR5 and C-erbB-2 as joint evaluation indicators of lymph node metastasis}

Compared with primary cancer tissues without lymph node metastasis, the tissues 
with lymph node metastasis had higher levels of CCR5 expression and C-erbB-2 membrane and cytoplasmic staining. When 2 biological markers served as the independent evaluation index, the expression of CCR5 and C-erbB-2 was higher in lymph node-negative tumor tissues than that in lymph node-positive tumor tissues $(\mathrm{P}<0.026$ and $\mathrm{P}<0.005$, respectively). When the 2 biological markers were tested simultaneously, the lymph node-positive tumor tissues showed higher expression of at least 1 marker. Expression in the lymph node-negative group was significantly lower than that in the lymph node-positive group $(\mathrm{P}=0.004$; Table 6$)$.

Table 6. Lymph node metastasis and its related factors.
\begin{tabular}{lcccc}
\hline Positive expression rate & Lymph node metastasis (\%) & Non-lymph node metastasis (\%) & P value & r \\
\hline CCR5 & $92.0(46 / 50)$ & $68.2(15 / 22)$ & 0.026 & 0.305 \\
C-erbB-2 & $54.0(27 / 50)$ & $18.2(4 / 22)$ & 0.005 & 0.333 \\
CCR5 and/or C-erbB-2 & $96.0(48 / 50)$ & $68.2(15 / 22)$ & 0.004 & 0.387 \\
\hline
\end{tabular}

\section{DISCUSSION}

Studies have shown that chemokine-receptor systems play an important role in tumor progression (Müller et al., 2001; Balkwill, 2003). Tumor cells secrete chemotactic factors in a variety of processes (Karnoub et al., 2007), which mediate tumor cell invasion and metastasis through binding with corresponding receptors. The role of CCR5 and its ligands in breast cancer is currently garnering more attention. Azenshtein et al. (2002) have found that RANTES expression in the CCR 5 ligand occurs in breast tissue and breast cancer cell lines T47D and MCF-7. It is also associated with the degree of malignancy of breast cancer and disease course. The higher the degree of malignancy and the later the course of the disease, the higher is the expression of RANTES. These results indicate that RANTES is involved in breast cancer. Some studies in Chinese populations have confirmed that CCR5 expression in invasive ductal breast cancer is associated with the progression of breast cancer and axillary lymph node metastasis (Wang et al., 2005; Li et al., 2009) using immunohistochemical methods. Tan et al. (2009) have found that high CCR5 mRNA expression in human breast cancer stem cells accompanied stronger invasion and metastasis capabilities than those of breast cancer cells, which may be a key factor in breast cancer metastasis.

In this study, we confirmed that CCR5 was significantly overexpressed in breast tissues and metastatic axillary lymph node tissues using immunohistochemistry methods. This expression was also positively correlated with C-erbB-2 expression and axillary lymph node metastasis. We concluded that CCR5 can be considered a new marker for predicting the prognosis of breast cancer. Furthermore, joint detection with C-erbB-2 can greatly improve its forecast sensitivity. This conclusion was confirmed on the molecular level. The results showed that CCR5 mRNA expression in breast cancer tissues was significantly higher than that in adjacent normal tissue and breast fibroadenoma tissue. CCR5 mRNA expression varied among different clinical stages: the later the stage, the higher the expression. In addition, CCR5 mRNA expression in metastatic axillary lymph node tissue was also higher than that in non-metastatic lymph node tissue. These findings further confirmed that CCR5 was associated with end-stage breast cancer and axillary lymph node metastasis of breast cancer on the gene level. A higher level of CCR5 expression was accompanied by a higher level of malignancy of the cancer, a higher likelihood of lymph node metastasis, and a worse prognosis. One study has confirmed 
that CCR5 ligand (CLL5) expression is higher at each stage of breast cancer than that in normal breast tissue (Wei et al., 2007). These results indicate that the interaction of CCR5 and its ligands may promote the progression and metastasis of invasive ductal breast cancer. Its possible mechanisms are as follows: 1) breast cancer cells produce CCL5, a chemoattractant for monocyte-macrophage cells to the tumor foci to generate oncogenic factors that promote breast cancer cell production of more CCL5. Thus, a vicious cycle of inflammatory cell infiltration and oncogenic factors expression occurs. 2) The interaction of CCR5 and CLL5 through the $G$ protein receptor coupling pathways eventually produces a variety of effects, including the stimulation and proliferation of tumor cells (Frederick and Clayman, 2001). CCR5 and CLL5 binding can also cause a rearrangement of the cytoskeleton and regulate actin cell-related exercise processes that include membrane folding and pseudopodia formation to induce tumor cell chemotactic migration (Zlotnik and Yoshie, 2000). Ultimately, it induces tumor cells to adhere to the membrane through the extracellular matrix and the vascular basement membrane to transfer them into blood circulation and to particular organs. Another study (Mañes et al., 2003) has found that CCR5 expression is negatively correlated with p53 wild-type gene expression in the progression of breast tumors. CCR5 may be involved in the progression of breast cancer in a p53 gene mutation-mediated process.

The involvement of CCR5 gene polymorphism in human immunodeficiency virus pathogenesis and treatment is currently a focus of attention; however, research on the association of CCR5 gene polymorphism and breast cancer is relatively limited. Degerli et al. (2005) has detected the CCR5 $\Delta 32$ genotype in normal Turkish subjects and patients with several types of cancer cells using PCR techniques. The result showed that CCR5 $\Delta 32$ heterozygosity may be an independent risk factor for Turks with breast cancer. In this study, agarose gel electrophoresis was used to detect the allele frequency of CCR5- $\Delta 32$. These alleles were not found in this study owing to the small sample size and lower mutation rate in the Chinese Han population. However, the reasons for this absence must be further analyzed.

In summary, this study confirmed the association between CCR5 and the progression of infiltrating ductal breast cancer. CCR5 showed a high level of association with axillary lymph node metastasis in the end stages of disease. Owing to the complexity of the chemotactic factor receptor network and tumor growth and metastasis, the CCR5-specific regulation process in breast cancer cells and its association with other chemokine receptors should be explored further. This study provides a new direction for the study of CCR5 antagonist-, inhibitor-, and other anti-tumortargeted therapies. Whether the CCR5 gene polymorphisms affect the incidence, development, treatment, and prognosis of breast cancer is especially worthy of further attention.

\section{ACKNOWLEDGMENTS}

Research supported by the Natural Science Foundation of Shandong (\#Y2007C090)

\section{REFERENCES}

\footnotetext{
Azenshtein E, Luboshits G, Shina S, Neumark E, et al. (2002). The CC chemokine RANTES in breast carcinoma progression: regulation of expression and potential mechanisms of promalignant activity. Cancer Res. 62: 1093-1102.

Balkwill F (2003). Chemokine biology in cancer. Semin. Immunol. 15: 49-55.

Degerli N, Yilmaz E and Bardakci F (2005). The delta32 allele distribution of the CCR5 gene and its relationship with certain cancers in a Turkish population. Clin. Biochem. 38: 248-252.
} 
Frederick MJ and Clayman GL (2001). Chemokines in cancer. Expert Rev. Mol. Med. 3: 1-18.

Karnoub AE, Dash AB, Vo AP, Sullivan A, et al. (2007). Mesenchymal stem cells within tumour stroma promote breast cancer metastasis. Nature 449: 557-563.

Li WL, Zhang Y, Meng FY, (2009). Changes in the expression of CCR5 and infiltrating ductal breast cancer axillary lymph node metastases [J]. Shandong Med. 49: 19-20.

Loetseher PM, Ugueeioni L, Bordoi M, (1998). CCR5 15 character is tie of Thl lymphocytes. Nature 391: 344-348.

Mañes S, Mira E, Colomer R, Montero S, et al. (2003). CCR5 expression influences the progression of human breast cancer in a p53-dependent manner. J. Exp. Med. 198: 1381-1389.

Muller A, Homey B, Soto H, Ge N, et al. (2001). Involvement of chemokine receptors in breast cancer metastasis. Nature 410: 50-56.

Tan C, Yi CH and Li JJ (2009). Human breast cancer stem cells, CCR5 expression and its significance. Wuhan Univ. J. Nat. Sci. 20: 379-382.

Wang D, Guo MY and Guo BY (2005). Chemokine receptor 5 expression in infiltrating ductal breast cancer tissue and its significance. Acta Sec. Mil. Med. Univ. 25: 657-659.

Wei W, Yao F and Tu Y (2007). Breast tissue chemoattractant factor 5 expression and its clinical significance. J. Cancer Prev. Treat. 14: 1475-1479.

Zlotnik A and Yoshie O (2000). Chemokines: a new classification system and their role in immunity. Immunity 12: 121127. 